\title{
Release of Polycyclic Aromatic Hydrocarbons and Heavy Metals from Rubber Crumb in Synthetic Turf Fields: Preliminary Hazard Assessment for Athletes
}

\author{
Letizia Marsili ${ }^{1 *}$, Daniele Coppola ${ }^{1}$, Nicola Bianchi ${ }^{1}$, Silvia Maltese ${ }^{1}$, Massimo Bianchi ${ }^{2}$ and Maria Cristina Fossi ${ }^{1}$ \\ ${ }^{1}$ Department of Physical Sciences, Earth and Environment, Siena University, Via Mattioli 4, 53100 Siena, Italy \\ ${ }^{2}$ Department of Political Science and International, Siena University, Via Mattioli 10, 53100 Siena, Italy
}

\begin{abstract}
Synthetic turf, made with an infill of rubber crumb from used tyres or virgin rubber, is now common in many sporting facilities. It is known that it contains compounds such as polycyclic aromatic hydrocarbons (PAHs) and heavy metals. We evaluated in nine samples of rubber crumb the total content of some heavy metals $(\mathrm{Zn}, \mathrm{Cd}, \mathrm{Pb}, \mathrm{Cu}, \mathrm{Cr}, \mathrm{Ni}, \mathrm{Fe})$ normally found in tyres by microwave mineralization and the levels of the 14 US EPA priority PAHs by Soxhlet extraction and HPLC analysis. The results showed high levels of PAHs and zinc in all rubber crumb samples compared to rubber granulate limits set by Italian National Amateur League (LND).

Following the precautionary principle, a risk assessment at $25^{\circ} \mathrm{C}$ was done, using the Average Daily Dose (ADD) assumed by athletes, expressed in terms of mass of contaminant per unit of body weight per day ( $\mathrm{mg} / \mathrm{kg}$ day), and the Lifetime Average Daily Dose $(L A D D)$ and then evaluating the Hazard Index $(\mathrm{HI})$ and the Cumulative Excess Cancer Risk $\left(\sum E C R\right)$. In the different rubber granulates samples the $\mathrm{HI}$ ranges from a minimum of $8.94 \times 10^{-7}$ to a maximum of $1.16 \times 10^{-6}$, while the $\sum \mathrm{ECR}$ ranges from a minimum of $4.91 \times 10^{-9}$ to a maximum of $1.10 \times 10^{-8}$

Finally, the aim of this study was to estimate the "hazard" for athletes inhaling PAHs released at the high temperatures this synthetic turf may reach. Then a sequence of proofs was carried out at $60^{\circ} \mathrm{C}$, a temperature that this rubber crumb can easily reach in sporting installations, to see whether PAH release occurs. The toxicity equivalent (TEQ) of evaporates from rubber crumb is not negligible and represents a major contribution to the total daily intake of PAHs by different routes.
\end{abstract}

Keywords: Synthetic turf; PAHs; Rubber crumb; Heavy metals; Hazard assessment

Abbreviations: ADD: Average Daily Dose; AT: Averaging Time; B[a]A: Benzo(a)antracene; B[a]P: Benzo(a)pyrene; B[b]F:Benzo(b) fluoranthene; $\mathrm{B}$ [ghi]Per: Benzo(g,h,i)perylene; $\mathrm{BaP}_{\text {eq: }}$ Benzo(a)pyrene equivalents; CDC: Centers for Disease Control and Prevention; $\mathrm{C}_{\mathrm{A}}$ : Concentration in Air; $\mathrm{C}_{\mathrm{F}}$ : Concentration in Field; Chry: Chrysene; DIN: Deutsches Institut für Normung / German Institute for Standardization; ECR: Excess Cancer Risk; $\Sigma E C R:$ Cumulative Excess Cancer Risk; ED: Exposure Duration; EF: Exposure Frequency; $\mathrm{EF}_{\mathrm{do}}$ : Daily Exposure Frequency; EPA: Environmental Protection Agency; Fl: Fluorene; Flt: Fluoranthene; HI: Hazard Index; HQ: Hazard Quotient; IA: Interested Area; IR: Inhalation Rate; LADD: Lifetime Average Daily Dose; PAH: Polycyclic Aromatic Hydrocarbons; PEF: Particulate Emission Factor; Pyr: Pyrene; RD: Reference Dose; SBRr: Styrene:Butadiene Recycled rubber; SF: Slope Factor; TEF: Toxic Equivalency Factors; TEQ: Toxic Equivalent Quantity.

\section{Introduction}

World population increase is accompanied by increasing consumption of resources. This makes recycling of materials extremely important to reduce waste. However, recycling itself is not enough, because it is necessary to understand if recycled materials have adverse effects on humans and environment, such as the case of used tyres, loaded of potentially toxic substances and recycled in synthetic turf. Today, synthetic turf is common in many sporting facilities. Created in the 1950s by the humanitarian Ford Foundation of New York and Chemstrand Corporation, it gained huge success in 1966 when used in the Astrodome stadium, Houston, Texas [1]. In the ' 70 s and ' 80 s, it was applied in many sports grounds in America and Canada, and was introduced into Europe in the mid-1980s. Softer new types of synthetic turf containing polyethylene were developed and introduced all over the world in the late 1990s [2]. Synthetic turfs differ in relation to their method of production and infill technique. Normally, the layer of infill consists of rubber crumb, which in a typical application reaches a thickness of $3 \mathrm{~cm}$, and is spread on a thin layer of sand [3]. The most common source of rubber crumb is recycled tyres (recycled styrene-butadiene rubber - SBRr); the diameter of the crumb can vary between 0.5 and $3 \mathrm{~mm}$ [4]. Hazardous substances in crumb rubber infill are primarily, volatile components (nitrosamines, xylenes), benzothiazoles, secondary amines, heavy metals (especially zinc) and polycyclic aromatic hydrocarbons (PAHs) [5]. In particular, the presence of zinc $(\mathrm{Zn})$ is due to zinc oxide that is used as a vulcanization aid in the rubber production process and PAHs come from higharomatic oil that is used as an additive in the production of tyres. In 2005, the Italian Ministry for the Environment allowed SBR crumb for synthetic grass courts in Italy [6], but there are still no European Union guidelines defining measures to protect the environment and human health in relation to SBRr in synthetic turf. The only standard to which manufacturers refer in producing SBRr crumb was published in 2002 by the German Institute for Standardization (DIN) establishing limits for certain heavy metals in soil, but with no reference to PAHs [7]. This standard was also chosen by the Italian National Amateur League (LND) in its "Regulations for the construction of latest generation artificial turf football fields", which defines soccer field parameters necessary for approval and use. Besides purely technical qualities, it

*Corresponding author: Letizia Marsili, Department of Physical Sciences, Earth and Environment, Siena University, Via Mattioli 4, 53100 Siena, Italy, Tel: +39 0577 232917; Fax: +39 0577 232930; E-mail: marsilil@unisi.it

Received November 22, 2014; Accepted January 20, 2015; Published January 25, 2015

Citation: Marsili L, Coppola D, Bianchi N, Maltese S, Bianchi M , Fossi MC (2015) Release of Polycyclic Aromatic Hydrocarbons and Heavy Metals from Rubber Crumb in Synthetic Turf Fields: Preliminary Hazard Assessment for Athletes. J Environ Anal Toxicol 5: 265. doi: 10.4172/2161-0525.1000265

Copyright: $\odot 2015$ Marsili L, et al. This is an open-access article distributed under the terms of the Creative Commons Attribution License, which permits unrestricted use, distribution, and reproduction in any medium, provided the original author and source are credited. 
also includes concentration limits for certain substances, including heavy metals and some high molecular weight PAHs (limits reflect those provided by Legislative Decree 152/2006 [8,9]. Sport grounds fitted with synthetic turf filled with crumb of recycled tyres may release dangerous particles in air, contaminate soil and groundwater with soluble contaminants leached by rain, and pose health hazards for residents and users due to inhalation of volatile substances [10]. Some coats for rubber granulates can effectively reduce emissions in the environment of these contaminants but they are not systematically used [11].

Though designed for sporting facilities, it is not uncommon to find synthetic grass in recreational parks and children's playgrounds. Synthetic turf may reach high temperatures: for example, on a day with an air temperature of $26^{\circ} \mathrm{C}$ in the early afternoon, synthetic surfaces may reach $60^{\circ} \mathrm{C}$, making it difficult to play on them [2]. The U.S. Center for Disease Control and Prevention (CDC) has not yet assessed the risks associated with exposure to dust released by rubber crumb from playing fields. As a precautionary measure, it issued general recommendations for users to minimize any potential risk, such as wash aggressively hand and body after playing, do not eat and drink on the field and do not use clothes and shoes after the activity for normal life [12]. Some studies have focused on levels of heavy metals, such as $\mathrm{Zn}$, or PAHs in tyre rubber, both in granulates and in leachate $[3,13-15]$ evaluating also the ecotoxicological effects in different organisms and humans[14,16-19]. In response to concern about human exposure through direct contact or inhalation, the principal aims of this study were: 1) to quantify the PAHs and heavy metals contained in rubber crumb from recycled tyres, produced before 2010 [20]. used in synthetic turf, to determine whether PAHs are released and at what concentrations, becoming bioavailable to synthetic turf users at high temperatures; 2 ) to estimate respiratory uptake by athletes training on these grounds.

\section{Materials and Methods}

\section{Sample collection}

Samples of nine different synthetic turfs from football fields in Tuscany and Lazio (Italy) were analyzed. Samples 1 to 5 were new and had not yet been spread on playing fields yet; samples 6 to 9 were obtained from fields that had been laid down for 1 to 8 years. The crumb of sample 5 was virgin rubber and not recycled tyres (Table 1). In the laboratory, the samples were kept at room temperature, in black bags, away from sunlight.

\section{Heavy metals analysis}

The samples were mineralized in a microwave oven (EPA Method 3052 modified in the Lab. (Bianchi, p.c.)). About $0.3 \mathrm{~g}$ of rubber crumb sample was placed in Teflon containers, spiked with $8 \mathrm{~mL}$ nitric acid $\left(\mathrm{HNO}_{3}\right)$ and $2 \mathrm{~mL}$ hydrogen peroxide $\left(\mathrm{H}_{2} \mathrm{O}_{2}\right)$, then transferred to a microwave oven. The solutions thus obtained were cooled to a final volume of $50 \mathrm{~mL}$ and concentrations of lead $(\mathrm{Pb})$, copper $(\mathrm{Cu})$, nickel $(\mathrm{Ni})$, zinc $(\mathrm{Zn})$, chromium $(\mathrm{Cr})$, cadmium $(\mathrm{Cd})$ and iron $(\mathrm{Fe})$ were evaluated. A blank was included in each series to check the purity of reagents and two tests of reference materials (ERM-EC680k and NISTSRM2710) with concentrations certified by the Community Bureau of Reference were performed to check analytical accuracy. $\mathrm{Cr}, \mathrm{Cu}$, $\mathrm{Ni}, \mathrm{Pb}$ and $\mathrm{Cd}$ concentrations were determined with PerkinElmer AAnalyst700 high-performance atomic absorption spectrometers with graphite furnace. $\mathrm{Zn}$ and $\mathrm{Fe}$ concentrations were determined with an Analytik Jena ContrAA700 acetylene flame atomic absorption spectrophotometer. All metal concentrations were expressed as the mean of three replicates in $\mu \mathrm{g} / \mathrm{g}$ on a dry weight basis.

\section{PAH analysis}

PAH extraction in rubber crumb: PAHs were extracted according to Griest and Caton [21,22] and Holoubek et al [22]. with some modifications [23]. About $1.0 \mathrm{~g}$ of rubber crumb was extracted with a mixture of $\mathrm{KOH} 2 \mathrm{M} /$ methanol (1:4) in a Soxhlet apparatus for $4 \mathrm{~h}$ at $75^{\circ} \mathrm{C}$. The mixture was extracted by shaking in separator funnels with $200 \mathrm{~mL}$ of cyclohexane. Liquid/liquid separation was performed to bring the PAH fraction into the supernatant. The liquid recovered was concentrated in a Rotavapor system, resuspended with $10 \mathrm{~mL}$ acetone/ hexane (1:1) and purified in a chromatographic column packed with 3 $\mathrm{cm}$ of Florisil, about $60-100$ US mesh, previously set at $120^{\circ} \mathrm{C}$ for $2 \mathrm{~h}$. Elution was carried out with $90 \mathrm{~mL}$ acetone/hexane (1:1). The organic fraction was concentrated and suspended in $0.5 \mathrm{~mL}$ acetonitrile for HPLC analysis.

PAH Extraction in evaporates of rubber crumb: Since synthetic fields can reach $60^{\circ} \mathrm{C}$ when the air temperature is about $25^{\circ} \mathrm{C}$, a method to evaluate release of PAHs at this temperature was used. Small flasks $(25 \mathrm{~mL})$ were filled with a quantity of rubber crumb up to $3 \mathrm{~cm}$ high, in order to simulate their thickness in a synthetic field. Then, the following steps were applied: 1) a closed trap packed with a bottom layer of cotton/ fiberglass and a $3 \mathrm{~cm}$ layer of Florisil, previously activated at $120^{\circ} \mathrm{C}$ for $2 \mathrm{~h}$, was placed on every flask; 2) the flask/trap system was kept at $60^{\circ} \mathrm{C}$ for about $5 \mathrm{~h}$ (assumed to be the average period at $25^{\circ} \mathrm{C}$ in a day) to capture the evaporates of rubber crumb; 3 ) liquid chromatography was then immediately performed using the trap as a column by pouring in $10 \mathrm{~mL}$ acetone/hexane $(1: 1)$ and then a further $90 \mathrm{~mL}$ of the same mixture; 4) the extract thus obtained was concentrated in a Rotavapor system and resuspended in $0.5 \mathrm{~mL}$ acetonitrile for HPLC analysis. This procedure (steps 1-4) was repeated three times to obtain three consecutive readings for each sample, thus determining whether or not the release of PAHs was continuous. The efficiency of the traps was validated with two different evaporation tests: first evaporation of the standard EPA 610 in acetonitrile (1/100) and, second evaporation, with the same amount of EPA $610(1 / 100)$ mixed with a rubber crumb sample $3 \mathrm{~cm}$ high. HPLC analysis showed that the efficiency of the traps was about the $90 \%$. In fact, in the first case, summing the amount of PAHs found in the evaporated to those found in the sample left in the flask, the value was almost like to the original amount of the standard EPA 610. In the other case of the standard mixed with the rubber crumb, there was a little matrix effect because the amount of PAHs found in the evaporated was lower (5-10\%) than those found in the evaporated of the standard alone.

PAH analysis: PAHs were analyzed by an HPLC/fluorescence system. PAHs were separated using a reversed-phase column (Supelcosil LC-18, $25 \mathrm{~cm} \times 4.6 \mathrm{~mm}$ i.d., $0.5 \mu \mathrm{m}$ particle size, pore size $120 \AA$ ) with an acetonitrile/water gradient from $60 \%$ to $100 \%$ acetonitrile for $20 \mathrm{~min}$, then isocratically for $10 \mathrm{~min}$. The flow rate was $1.5 \mathrm{~mL} / \mathrm{min}$. The mobile-phase was degassed with a helium stream. An external standard consisting of 16 PAHs from Supelco (EPA 610) was used. Fourteen PAHs were analyzed and the results expressed in ng/g. Recoveries were $80-98 \%$. The detection limit, calculated at a signal-tonoise ratio of three, was $0.1 \mathrm{ng} / \mathrm{g}$ for all PAHs. Assay reproducibility was determined by five replicate analyses of a single sample: the coefficient of variation was $1-3 \%$, depending on the compound. Blanks contained undetectable amounts of PAHs. 


\begin{tabular}{|c|c|c|c|c|c|c|c|c|c|c|c|}
\hline Sample & Sample 1 & Sample 2 & Sample 3 & Sample 4 & Sample 5 & Sample 6 & Sample 7 & Sample 8 & Sample 9 \\
\hline $\begin{array}{l}\text { Years since } \\
\text { installation }\end{array}$ & 0 & 0 & 0 & 0 & 0 & 8 & 2 \\
\hline
\end{tabular}

Table 1: Years of installation in sporting infrastructure of the rubber crumb samples analysed.

\section{Results and Discussion}

\section{Heavy metal concentrations in rubber crumb}

Table 2 shows the concentrations of heavy metals (cadmium, lead, chromium, nickel, copper, zinc and iron; $\mathrm{mg} / \mathrm{kg}$ ) in rubber crumb samples and the maximum admissible concentration set by the Italian National Amateur League [9]. These limits are identical to those of Dlgs. 152/2006 [8] for public parks and private and residential land.

Lead, chromium, nickel and copper were well below the limits in all samples. Three samples exceeded the limit for cadmium, two being new (samples 4 and 5) and the third already installed (sample 6). In the case of zinc, all samples recorded high concentrations: sample 1 showed the lowest concentration of zinc, exceeding the limit by a factor of more than 20; the worst case was sample 4, exceeding the limit by a factor of nearly 90. Concentrations were quite similar to those of the study of Bocca et al. [13], except for cadmium that was always below the limit in the cited study. Concentrations of iron were quite similar to each other, except for sample 2 that showed a particularly high peak.

Zinc values are in line with other studies concerned with it: Verschoor [3] not only assessed the quantity of zinc in the rubber infill, but also the amount released, showing that the aging of rubber has a high impact on the release of zinc, which the author estimated as an annual average of $50 \mathrm{mg} / \mathrm{kg}$ of rubber. The concentration of $\mathrm{Zn}$ found in leachate was $1.3 \mathrm{mg} / \mathrm{L}$, which is above the limit imposed by the Dutch Soil Quality law [24,25].

Another study evaluated the bioavailability of certain metals and PAHs in human digestive fluids, assuming ingestion of crumb from synthetic fields [26]. Their results showed that $\mathrm{Zn}$ in particular exceeded the limits of the Department of Environmental Conservation (DEC) of New York State [27] for soil (2200 ppm), while the lead content in rubber crumb never exceeded these limits, but was very bioavailable in synthetic gastric fluid, thus representing a potential risk to athletes.

\section{PAH levels in rubber crumb}

It proved possible to identify and quantify the PAHs in all samples. All were priority PAHs according to USEPA [28] and some are known to be powerful carcinogens (Table 3) [29-32]. The total PAHs in tables and graphs are the sum of individual PAHs, while the carcinogenic PAHs are only those which are carcinogenic according to at least three classifications. Although benzo(a)pyrene (B[a]P) only accounted for $10-20 \%$ of the carcinogenic compounds, it is used by the European Commission Regulation 1881/2006 as an indicator of contamination by the 16 priority PAHs [33].

Table 4 shows the levels of single PAHs (ng/g) detected in samples 1 to 9 . Samples 1 to 5 were obtained before they were spread on playing surfaces, whereas the samples 6 to 9 were collected directly from the fields and had been in place for 1 to 8 years. The two last rows of Table 4 show total PAH levels, obtained by summing all the PAHs quantified, and carcinogenic PAH levels, obtained by summing carcinogenic PAHs of Table 3.

Figure 1 compares levels of total PAHs and carcinogenic PAHs in rubber crumb from the various football fields. Very high levels of total PAHs were found in samples 2, 9 and 1. Lower levels were found in samples 3, 6, 7 and 8, indicating a difference between new samples and those already installed in soccer fields. Indeed, the load of PAHs was appreciably lower in samples 6,7 and 8 (installed 3 to 8 years ago) than in the other samples. This shows that once installed, these fields lose part of their toxic load in the time. This fact is important for assessing toxicological hazard to athletes, therefore they are chronically exposed to these compounds.

Comparing the relative percentages of all PAHs on total PAHs of the different samples (Figure $2 \mathrm{~A}-\mathrm{C}$ ), we noted that the highest PAHs in all samples, except sample 5 , were benzo(b)fluoranthene $(B[b] F)$ (samples 1,2,6 and 9) or pyrene (Pyr) (samples 3, 4, 7 and 8) but always followed by $\mathrm{B}[\mathrm{b}] \mathrm{F}$. The fingerprint of sample 5 (natural rubber crumb, not recycled tyres) showed a high concentration of fluorene (Fl), followed by Pyr, fluoranthene (Flt) and $\mathrm{B}[\mathrm{b}] \mathrm{F}$, unlike the other footprints. Although absolute levels of PAHs were high in this sample (Table 4), the three most abundant PAHs (Fl, Pyr and Flt) are not regarded as particularly hazardous or carcinogenic to humans and therefore this type of natural rubber crumb can be considered less toxic.

Table 5 shows the levels of those PAHs $(\mathrm{mg} / \mathrm{kg})$ of which the maximum admissible concentration is established [8], detected in the rubber crumb samples analyzed for this study. The Decree reported threshold values of concentration for some PAHs in soils and even if the comparison with the present data was not direct it could give some indications. All samples exceeded the limit for $\mathrm{B}[\mathrm{b}] \mathrm{F}$ and benzo(g,h,i) perylene ( $\mathrm{B}[\mathrm{ghi}]$ Per); in the case of $\mathrm{B}[\mathrm{b}] \mathrm{F}$, sample 2 exceeded the limit by a factor of about 30 , and samples 1 and 9 by a factor of about 20 . No crumb exceeded the limit for chrysene (Chry).

\section{PAH levels in evaporates of rubber crumb}

Table 6 shows the levels of benzo(a)anthracene (B[a]A), Chry, B[a] $\mathrm{P}$ and $\mathrm{B}$ [ghi]Per, among the most toxic high molecular weight PAHs detected in evaporates of nine rubber crumbs. We have taken only these PAHs because, when the evaporation test was repeated three times to obtain three consecutive readings for each sample, were the only PAHs which standard deviation (S.D.) was below the mean value in all nine samples. Among all samples, turf fields 9 and 1 released particularly high levels of all considered compounds. Evaporation tests showed that the releasing of four PAHs into the air by rubber crumb did not decrease with the time, suggesting chronic contamination in areas fitted with synthetic turf filled with rubber crumb.

It was also evaluated the mean times for total release of these four PAHs from the samples (Table 7). In theory, considering for each compound the total amount present in the rubber crumb samples and the amount found in the evaporated samples, we can estimate that for the new turf fields are necessary from a minimum of 811 times (sample 3 ) to a maximum of 4423 times (sample 2) to exhaust emissions of these compounds when the turf temperature reaches $60^{\circ} \mathrm{C}$, then when the atmospheric temperature is $25^{\circ} \mathrm{C}$. Regarding the used samples, in the same conditions of temperature, are required from a minimum of 346 times (sample 7) to a maximum of 655 times (sample 6). Assuming solar radiation keeps atmospheric temperature at $25^{\circ} \mathrm{C}$ for at least $5 \mathrm{~h}$ /day (heating experimental time in the Lab.) for 5 months of the year, there are 150 suitable days per year. Ignoring other sources of elimination, such as rainwater or washing that cause leaching and cooler days when the crumb still becomes warm, it would hypothetically take a minimum 


\begin{tabular}{|c|c|c|c|c|c|c|c|}
\hline & $\begin{array}{c}\mathbf{C d} \\
(\mathbf{m g} / \mathbf{k g})\end{array}$ & $\begin{array}{c}\mathbf{P b} \\
(\mathbf{m g} / \mathbf{k g})\end{array}$ & $\begin{array}{c}\mathbf{C r} \\
(\mathbf{m g} / \mathbf{k g})\end{array}$ & $\begin{array}{c}\mathbf{N i} \\
(\mathbf{m g}(\mathbf{k g})\end{array}$ & $\begin{array}{c}\mathbf{C u} \\
(\mathbf{m g} / \mathbf{k g})\end{array}$ & $\begin{array}{c}\mathbf{Z n} \\
(\mathbf{m g} / \mathbf{k g})\end{array}$ & $\begin{array}{c}\mathbf{F e} \\
(\mathbf{m g} / \mathbf{k g})\end{array}$ \\
\hline Sample 1 & 1.81 & 27.86 & 7.92 & 26.12 & 46.42 & $\mathbf{3 4 7 4 . 0 0}$ & 489.60 \\
\hline Sample 2 & 1.77 & 17.51 & 17.52 & 9.86 & 39.96 & $\mathbf{3 7 3 2 . 0 0}$ & 7256.00 \\
\hline Sample 3 & 0.47 & 13.97 & 4.12 & 4.11 & 5.59 & $\mathbf{5 3 1 4 . 0 0}$ & 129.12 \\
\hline Sample 4 & $\mathbf{2 . 0 5}$ & 33.58 & 3.34 & 5.27 & 84.49 & $\mathbf{1 3 2 0 2 . 0 0}$ & 657.40 \\
\hline Sample 5 & $\mathbf{2 . 6 8}$ & 11.23 & 2.84 & 8.95 & 9.50 & $\mathbf{6 4 6 2 . 0 0}$ & 355.40 \\
\hline Sample 6 & $\mathbf{2 . 3 8}$ & 22.84 & 2.95 & 5.43 & 27.47 & $\mathbf{4 8 6 6 . 0 0}$ & 1577.40 \\
\hline Sample 7 & 0.47 & 10.76 & 3.58 & 5.14 & 5.49 & $\mathbf{4 1 6 8 . 0 0}$ & 543.00 \\
\hline Sample 8 & 1.51 & 29.44 & 1.91 & 3.90 & 14.43 & $\mathbf{6 0 0 6 . 0 0}$ & 262.20 \\
\hline Sample 9 & 1.53 & 38.99 & 5.37 & 5.75 & 65.11 & $\mathbf{4 1 9 4 . 0 0}$ & 346.80 \\
\hline $\begin{array}{c}\text { Limit } \\
\text { (LND, 2011) }\end{array}$ & $\mathbf{2 . 0 0}$ & $\mathbf{1 0 0 . 0 0}$ & $\mathbf{1 5 0 . 0 0}$ & $\mathbf{1 2 0 . 0 0}$ & $\mathbf{1 2 0 . 0 0}$ & $\mathbf{1 5 0 . 0 0}$ & $\mathbf{N}$ \\
\hline
\end{tabular}

Table 2: Levels $(\mathrm{mg} / \mathrm{kg}$ ) of cadmium, lead, chromium, nickel, copper, zinc and iron in samples of rubber crumb. The triple horizontal line separates new crumb (samples $1-5$ ) and crumb sampled from sporting installations (samples 6-9). Values in bold exceeded the limits set by the Italian National Amateur League reported in the last row.

\begin{tabular}{|c|c|c|c|c|c|c|c|c|c|c|c|c|c|}
\hline Compound & Abbreviation & $\begin{array}{c}\text { Structure } \\
\text { (\# of rings) }\end{array}$ & Formula & $\begin{array}{l}\text { Molecular } \\
\text { weight (g/ } \\
\text { mol) }\end{array}$ & $\begin{array}{c}\text { Solubility } \\
(\mathrm{mg} / \mathrm{L})\end{array}$ & $\begin{array}{l}\text { Melting } \\
\text { point } \\
\left({ }^{\circ} \mathrm{C}\right)\end{array}$ & $\begin{array}{l}\text { Boiling } \\
\text { point } \\
\left({ }^{\circ} \mathrm{C}\right)\end{array}$ & $\begin{array}{c}\text { Vapor } \\
\text { tension }(\mathrm{Pa}) \\
\text { at } 25^{\circ} \mathrm{C}\end{array}$ & $\begin{array}{c}\text { Coefficient } \\
\text { octanol/ } / \mathrm{H}_{2} \mathrm{O} \\
\left(\log \mathrm{K}_{\text {ow }}\right)\end{array}$ & $\begin{array}{l}\text { Carcinogenicity } \\
\text { IARC (2008) }\end{array}$ & $\begin{array}{c}\text { Carcinogenicity } \\
\text { NTP (2005) }\end{array}$ & $\begin{array}{l}\text { Carcinogenicity } \\
\text { IPCS (1998) }\end{array}$ & $\begin{array}{c}\text { Carcinogenicity NRCC } \\
\text { (1983) }\end{array}$ \\
\hline Naphthalene (S) & Naph & 2 & $\mathrm{C}_{10} \mathrm{H}_{8}$ & 128.17 & 31 & 81 & 217.9 & 10.4 & 3.40 & 2B & & (?) & 0 \\
\hline Acenaphthene (S) & Ace & 3 & $\mathrm{C1}_{2} \mathrm{H}_{8}$ & 154.21 & 3.8 & 95 & 279 & $2.9 \times 10^{-1}$ & 3.92 & 3 & & (?) & 0 \\
\hline Fluorene (S) & $\mathrm{FI}$ & 3 & $\mathrm{C}_{13} \mathrm{H}_{10}$ & 166.22 & 1.9 & $115-116$ & 295 & $8.0 \times 10^{-2}$ & 4.18 & 3 & & - & 0 \\
\hline Phenanthrene (S) & Phen & 3 & $\mathrm{C}_{14} \mathrm{H}_{10}$ & 178.23 & 1.1 & 100.5 & 340 & $1.6 \times 10^{-2}$ & 4.60 & 3 & & (?) & 0 \\
\hline Anthracene (S) & Ant & 3 & $\mathrm{C}_{14} \mathrm{H}_{10}$ & 178.23 & 0.045 & 216.4 & 342 & $8.0 \times 10^{-4}$ & 4.50 & 3 & & - & 0 \\
\hline Fluoranthene (C) & Flt & 4 & $\mathrm{C}_{16} \mathrm{H}_{10}$ & 202.26 & 0.26 & 108.8 & 375 & $1.2 \times 10^{-3}$ & 5.22 & 3 & & + & 0 \\
\hline Pyrene (C) & Pyr & 4 & $\mathrm{C}_{16} \mathrm{H}_{10}$ & 202.26 & 0.132 & 150.4 & 393 & $6.0 \times 10^{-4}$ & 5.18 & 3 & & (?) & 0 \\
\hline Benzo(a)anthracene (C) & $\mathrm{B}[\mathrm{a}] \mathrm{A}$ & 4 & $\mathrm{C}_{18} \mathrm{H}_{12}$ & 228.29 & 0.011 & 160.7 & 400 & $2.8 \times 10^{-5}$ & 5.61 & 2B & Yes & + & + \\
\hline Chrysene (C) & Chry & 4 & $\mathrm{C}_{18} \mathrm{H}_{12}$ & 228.29 & 0.0015 & 253.8 & 448 & $\begin{array}{l}8.4 \times 10^{-5} \\
\left(20^{\circ} \mathrm{C}\right)\end{array}$ & 5.91 & 2B & Yes & + & \pm \\
\hline Benzo(b)fluoranthene (C) & $\mathrm{B}[\mathrm{b}] \mathrm{F}$ & 5 & $\mathrm{C}_{20} \mathrm{H}_{12}$ & 252.32 & 0.0015 & 168.3 & 481 & $\begin{array}{l}6.7 \times 10^{-5} \\
\left(20^{\circ} \mathrm{C}\right)\end{array}$ & 6.12 & $2 \mathrm{~B}$ & Yes & + & ++ \\
\hline Benzo(k)fluoranthene (C) & $\mathrm{B}[\mathrm{k}] \mathrm{F}$ & 5 & $\mathrm{C}_{20} \mathrm{H}_{12}$ & 252.32 & 0.0008 & 215.7 & 480 & $\begin{array}{l}1.3 \times 10^{-8} \\
\left(20^{\circ} \mathrm{C}\right)\end{array}$ & 6.84 & 2B & Yes & + & 0 \\
\hline Benzo(a)pyrene (C) & $\mathrm{B}[\mathrm{a}] \mathrm{P}$ & 5 & $\mathrm{C}_{20} \mathrm{H}_{12}$ & 252.32 & 0.0038 & 178.1 & 496 & $7.3 \times 10^{-7}$ & 6.50 & 1 & Yes & + & +++ \\
\hline Dibenz(a,h)anthracene (C) & $\mathrm{D}[\mathrm{ah}] \mathrm{A}$ & 6 & $\mathrm{C}_{22} \mathrm{H}_{14}$ & 278.35 & 0.0005 & 266.6 & 524 & $\begin{array}{l}5.3 \times 10^{-8} \\
\left(20^{\circ} \mathrm{C}\right)\end{array}$ & 6.50 & $2 A$ & Yes & + & +++ \\
\hline Benzo(g,h,i)perylene (C) & B[ghi]Per & 6 & $\mathrm{C}_{22} \mathrm{H}_{12}$ & 276.34 & 0.00026 & 278.3 & 545 & $1.4 \times 10^{-8}$ & 7.10 & 3 & & (?) & 0 \\
\hline \multirow[t]{2}{*}{ Indeno(1,2,3cd)pyrene $(C)$} & $\mathrm{I}[1,2,3-\mathrm{cd}] \mathrm{P}$ & 6 & $\mathrm{C}_{22} \mathrm{H}_{12}$ & 276.34 & 0.062 & 163.6 & 536 & $\begin{array}{l}1.3 \times 10^{-8} \\
\left(20^{\circ} \mathrm{C}\right)\end{array}$ & 6.58 & $2 \mathrm{~B}$ & Yes & + & + \\
\hline & & & & & & & & & & \multicolumn{2}{|c|}{$\begin{array}{c}1 \text { demonstrated carcinogenic } \\
\text { 2A probable carcinogenicity } \\
\text { 2B possible carcinogenicity } \\
\text { 3 carcinogenicity not demonstrated }\end{array}$} & $\begin{array}{l}\text { + positive } \\
\text { - negative } \\
\text { ? uncertain } \\
\text { () insufficient } \\
\text { evidence }\end{array}$ & $\begin{array}{l}0 \text { not carcinogenic } \\
\pm \text { uncertain } \\
\text { carcinogenicity } \\
+ \text { carcinogenic }\end{array}$ \\
\hline
\end{tabular}

Table 3: PAH compounds detected in rubber crumb samples. Abbreviations: S - petrogenic; C - pyrogenic. Grey shades indicate carcinogenicity, determined in at least three published studies, and degree of carcinogenicity.

\begin{tabular}{|c|c|c|c|c|c|c|c|c|c|}
\hline & $\begin{array}{c}\text { Sample } 1 \\
\text { (ng/g) }\end{array}$ & $\begin{array}{c}\text { Sample } 2 \\
\text { (ng/g) }\end{array}$ & $\begin{array}{c}\text { Sample } 3 \\
\text { (ng/g) }\end{array}$ & $\begin{array}{c}\text { Sample } 4 \\
\text { (ng/g) }\end{array}$ & $\begin{array}{c}\text { Sample } 5 \\
\text { (ng/g) }\end{array}$ & $\begin{array}{c}\text { Sample } 6 \\
\text { (ng/g) }\end{array}$ & $\begin{array}{c}\text { Sample } 7 \\
\text { (ng/g) }\end{array}$ & $\begin{array}{c}\text { Sample } 8 \\
\text { (ng/g) }\end{array}$ & $\begin{array}{c}\text { Sample } 9 \\
\text { (ng/g) }\end{array}$ \\
\hline Naphthalene & 774.28 & 2039.61 & 360.19 & 804.53 & 424.87 & 246.14 & 407.59 & 223.32 & 1136.00 \\
\hline Acenaphthene & 7297.50 & 10148.88 & 352.12 & 4200.53 & 416.15 & 405.31 & 1309.41 & 508.71 & 6321.31 \\
\hline Fluorene & 10367.21 & 11025.47 & 426.81 & 1347.92 & 4944.42 & 1152.60 & 528.52 & 1665.02 & 7145.12 \\
\hline Phenanthrene & 708.74 & 1160.10 & 146.90 & 1560.01 & 149.00 & 247.79 & 76.03 & 37.92 & 1013.08 \\
\hline Anthracene & 80.30 & 138.12 & 38.25 & 282.62 & 44.56 & 76.39 & 7.64 & 34.59 & 182.28 \\
\hline Fluoranthene & 2939.37 & 3740.04 & 872.96 & 1979.53 & 2243.22 & 710.43 & 993.99 & 817.50 & 3244.74 \\
\hline Pyrene & 5670.11 & 6729.04 & 3983.32 & 5974.83 & 3800.41 & 1643.56 & 2144.43 & 1909.15 & 10280.99 \\
\hline Benzo(a)anthracene & 1166.03 & 1612.58 & 92.28 & 440.21 & 267.10 & 115.46 & 41.37 & 5.38 & 389.40 \\
\hline Chrysene & 2898.05 & 3422.21 & 923.00 & 1396.91 & 700.38 & 243.57 & 921.07 & 622.18 & 916.56 \\
\hline Benzo(b)fluoranthene & 11103.33 & 15715.42 & 1149.65 & 4569.85 & 1563.07 & 1899.14 & 1248.07 & 1440.33 & 10185.76 \\
\hline Benzo(k)fluoranthene & 679.05 & 1203.44 & 68.25 & 504.87 & 353.09 & 126.77 & 224.24 & 611.64 & 3615.88 \\
\hline Benzo(a)pyrene & 256.10 & 464.58 & 119.81 & 229.96 & 165.92 & 265.10 & 60.28 & 51.72 & 662.56 \\
\hline Dibenz(a,h)anthracene & 464.36 & 362.12 & 192.90 & 72.75 & 426.97 & 344.52 & 109.13 & 134.76 & 573.26 \\
\hline Benzo(g,h,i)perylene & 902.89 & 449.76 & 395.63 & 418.68 & 585.24 & 543.82 & 239.69 & 344.92 & 475.49 \\
\hline Total PAHs & 45307.32 & 58211.37 & 9122.05 & 23783.19 & 16084.40 & 8020.60 & 8311.45 & 8407.13 & 46142.43 \\
\hline Carcinogenic PAHs & 16566.92 & 22780.35 & 2545.89 & 7214.55 & 3476.52 & 2994.56 & 2604.16 & 2866.02 & 16343.42 \\
\hline
\end{tabular}

Table 4: Levels of PAHs (ng/g) detected in nine samples of rubber crumb. The triple vertical line separates new crumb (1-5) from crumb sampled directly from sporting facilities (6-9). 


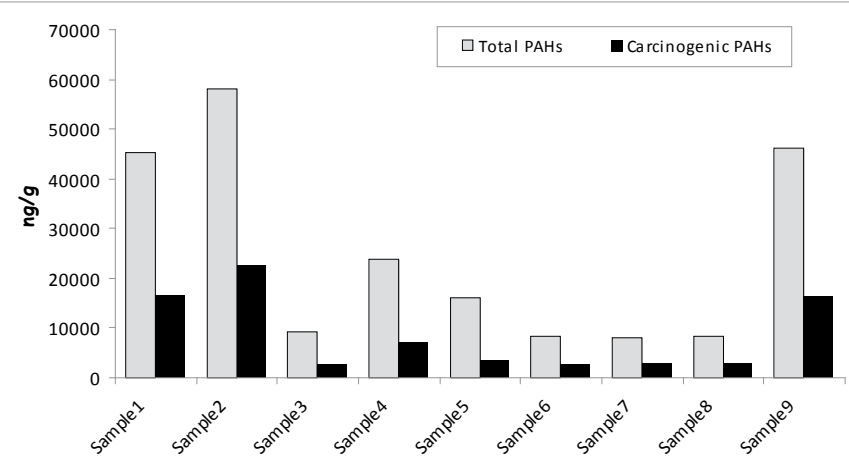

Figure 1: Levels of total PAHs and carcinogenic PAHs (ng/g) in samples of rubber crumb.
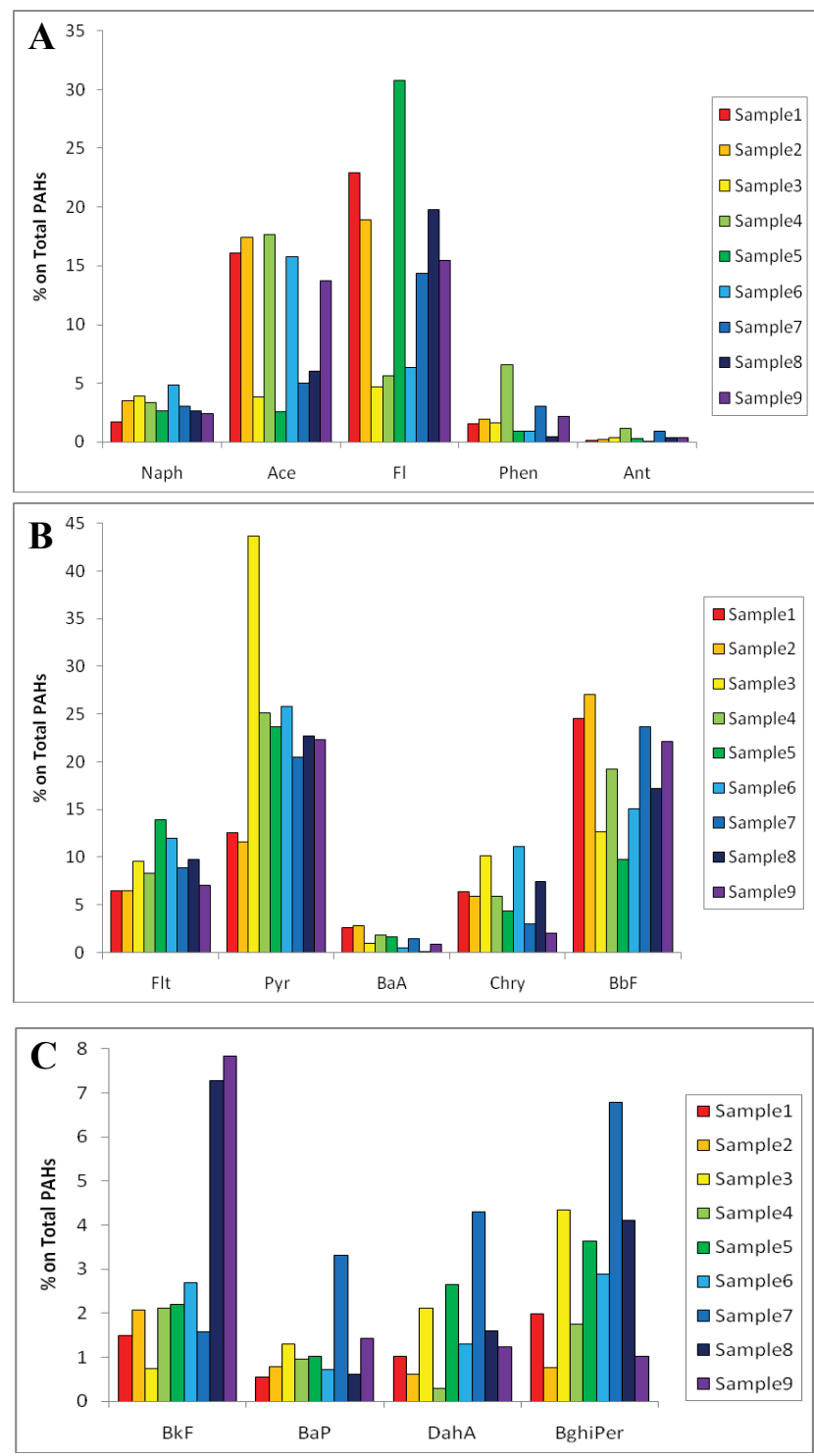

Figure 2: A-B-C Relative percentages of all PAH fingerprints on total PAHs of the different samples.

of 2 years (sample 7) to a maximum of about 29 years (sample 2) to reach theoretical zero concentration of PAHs.

\section{Risk assessment for PAH inhalation from synthetic fields}

The approach to assess human health risks through the inhalation route in the synthetic turf fields, plans to consider field surface as soil surface [24]. Then, if field surface does not reach a temperature of $25^{\circ} \mathrm{C}$, the contaminant release in air can be associated to wind erosion and volatilization and the inhalation risk must consider also the contaminated dust resuspension. This site-specific inhalation risk evaluation that we have conducted on the rubber granulates of the nine synthetic fields, follows the recommendations of the Dlgs. 152/06 [8] and the indication of the technical procedure issued by APAT [34]. This evaluation procedure is applied separately on each pollutant and, at the end, all individual risk values obtained are summed. In order to proceed to this estimation, it is important to know the particulate emission factor (PEF) of outdoor matter of the survey site. We considered PEF equal to PM10 $\times 10^{-6} \mathrm{~kg} / \mathrm{mg}$, where PM10 are the levels of total inhalable dusts $\left(\mathrm{mg} / \mathrm{m}^{3}\right)$ potentially containing PAHs, assuming that all the particles present in the air as PM10 result from the volatilization of particles from the field, and not as an input from the wide variety of anthropogenic and crustal sources. Then, the following results are overestimated and they must be considered as extreme worst case screening. The precautionary principle is applied taking into account the highest average concentration of PM10 recorded in 2010 in Tuscany (since 8 turfs of 9 came from Tuscany) which is PM10 = $0.0517 \mathrm{mg} / \mathrm{m}^{3}$. Considering a punctiform source of contamination, it is possible to evaluate the contaminant concentration in air $\left(\mathrm{C}_{\mathrm{A}}\right)$ given by $\mathrm{C}_{\mathrm{A}}=$ contaminant concentration in field $\left(\mathrm{C}_{\mathrm{F}}\right)(\mathrm{mg} / \mathrm{kg}) \times \mathrm{PEF}$. In this way it is possible to calculate the Average Daily Dose (ADD), assumed by the athletes, expressed in terms of mass of contaminant per unit of body weight per day ( $\mathrm{mg} / \mathrm{kg}$ day). The ADD is calculated to evaluate toxic effects taking into consideration the $\mathrm{C}_{\mathrm{A}}$ values, the inhalation rate (IR) of an athlete $\left(3.6 \mathrm{~m}^{3} / \mathrm{h}\right)$, the daily exposure frequency $\left(\mathrm{EF}_{\mathrm{do}}\right)(2$ $\mathrm{h} / \mathrm{d})$, the exposure frequency $(\mathrm{EF})$ in a year $(208 \mathrm{~d} /$ year $)$, the exposure duration (ED) (20 years), the body weight (BW) $(70 \mathrm{~kg}$ ) and the averaging time (AT) $(20$ years $\mathrm{x} 365 \mathrm{~d} /$ year):

$$
\mathrm{ADD}=\left(\mathrm{C}_{\mathrm{A}} \times \mathrm{IR}_{\mathrm{BEF}} \times \mathrm{EF} \times \mathrm{ED}\right) /(\mathrm{BW} \times \mathrm{AT})
$$

Furthermore, the Lifetime Average Daily Dose (LADD), used for the evaluation of carcinogenic effects, is calculated simply with the same parameters of ADD, except the Averaging Time (AT) that for carcinogenic effects considers 70 years ( 70 years x $365 \mathrm{~d} /$ year).

Starting from ADD and LADD values, in the last step it is possible to calculate a Hazard Quotient (HQ) as an indicator of risks associated with health effects other than cancer, and Excess Cancer Risk (ECR) as the incremental probability of an exposed person developing cancer over

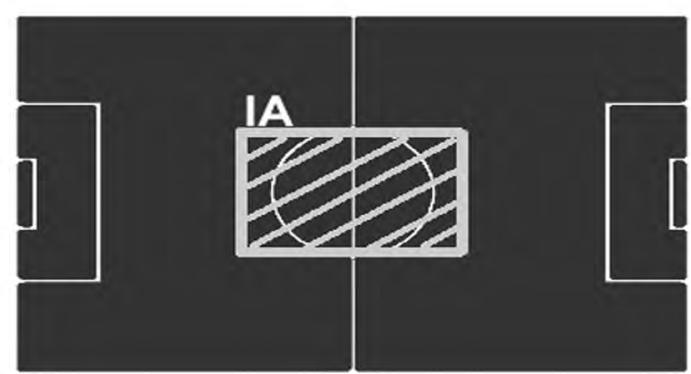

Figure 3: The Interested Area (IA) of size $18 \times 32 \mathrm{~m}\left(576 \mathrm{~m}^{2}\right)$ in the central position of a regular soccer field. 


\begin{tabular}{|c|c|c|c|c|c|c|c|c|}
\hline & Pyr (mg/kg) & B(a)A (mg/kg) & Chry (mg/kg) & $B[b] F(m g / k g)$ & $B(k) F(m g / k g)$ & $B(a) P(m g / k g)$ & $\mathrm{D}(\mathrm{ah}) \mathrm{A}$ (mg/kg) & $\mathrm{B}(\mathrm{ghi}) \operatorname{Per}(\mathrm{mg} / \mathrm{kg})$ \\
\hline Sample 1 & 5.67 & 1.17 & 2.90 & 11.10 & 0.68 & 0.26 & 0.46 & 0.90 \\
\hline Sample 2 & 6.73 & 1.61 & 3.42 & 15.72 & 1.20 & 0.46 & 0.36 & 0.45 \\
\hline Sample 3 & 3.98 & 0.09 & 0.92 & 1.15 & 0.07 & 0.12 & 0.19 & 0.40 \\
\hline Sample 4 & 5.97 & 0.44 & 1.40 & 4.57 & 0.50 & 0.23 & 0.07 & 0.42 \\
\hline Sample 5 & 3.80 & 0.27 & 0.70 & 1.56 & 0.35 & 0.17 & 0.43 & 0.59 \\
\hline Sample 6 & 1.64 & 0.12 & 0.24 & 1.90 & 0.13 & 0.27 & 0.34 & 0.54 \\
\hline Sample 7 & 2.14 & 0.04 & 0.92 & 1.25 & 0.22 & 0.06 & 0.11 & 0.24 \\
\hline Sample 8 & 1.91 & 0.01 & 0.62 & 1.44 & 0.61 & 0.05 & 0.13 & 0.34 \\
\hline Sample 9 & 10.28 & 0.39 & 0.92 & 10.19 & 3.62 & 0.66 & 0.57 & 0.48 \\
\hline $\begin{array}{c}\text { Limit (Dlgs } \\
152 / 2006)\end{array}$ & 5.00 & 0.50 & 5.00 & 0.50 & 0.50 & 0.10 & 0.10 & 0.10 \\
\hline
\end{tabular}

Table 5: Levels of PAHs (mg/kg) with maximum admissible concentration known detected in samples and the limits set by the Legislative Decree 152/2006. The triple horizontal line separates new crumb (samples 1-5) from crumb sampled from sporting installations (samples 6-9). Values in bold exceeded the limit.

\begin{tabular}{|c|c|c|c|c|c|c|c|c|}
\hline & \multicolumn{2}{|c|}{ Benzo(a)anthracene (ng/g) } & \multicolumn{2}{|c|}{ Chrysene (ng/g) } & \multicolumn{2}{|c|}{ Benzo(a)pyrene (ng/g) } & \multicolumn{2}{|c|}{ Benzo(g,h,i)perylene $(\mathrm{ng} / \mathrm{g})$} \\
\hline & Mean & S.D. & Mean & S.D. & Mean & $S . D$. & Mean & S.D. \\
\hline Sample 1 & 0.43 & 0.14 & 5.82 & 3.18 & 0.48 & 0.32 & 0.58 & 0.30 \\
\hline Sample 2 & 0.16 & 0.07 & 1.46 & 0.07 & 0.15 & 0.10 & 0.43 & 0.17 \\
\hline Sample 3 & 0.14 & 0.06 & 1.43 & 0.42 & 0.12 & 0.02 & 0.42 & 0.19 \\
\hline Sample 4 & 0.15 & 0.10 & 1.30 & 0.57 & 0.11 & 0.07 & 0.50 & 0.23 \\
\hline Sample 5 & 0.27 & 0.18 & 1.06 & 0.09 & 0.21 & 0.06 & 0.62 & 0.50 \\
\hline Sample 6 & 0.16 & 0.05 & 1.73 & 1.33 & 0.28 & 0.19 & 0.68 & 0.36 \\
\hline Sample 7 & 0.18 & 0.07 & 2.26 & 1.42 & 0.26 & 0.11 & 0.64 & 0.28 \\
\hline Sample 8 & 0.28 & 0.06 & 1.32 & 0.29 & 0.19 & 0.02 & 0.49 & 0.09 \\
\hline Sample 9 & 0.49 & 0.66 & 2.53 & 1.08 & 0.89 & 0.70 & 1.28 & 0.07 \\
\hline
\end{tabular}

Table 6: Levels (ng/g) of benzo(a)anthracene, chrysene, benzo(a)pyrene and benzo(g,h,i)perylene in evaporates of rubber crumb samples at $60^{\circ} \mathrm{C}$.

\begin{tabular}{|c|c|c|}
\hline & Mean Time (days at atmospheric T=25 ${ }^{\circ}$ C) & 1325 \\
\hline Sample 1 & 4423 \\
\hline Sample 2 & 811 \\
\hline Sample 3 & 1734 & 1047 \\
\hline Sample 4 & 846 & 3990 \\
\hline Sample 5 & 655 & 185 \\
\hline Sample 6 & 346 & 150 \\
\hline Sample 8 & 410 & 396 \\
\hline Sample 9 & 568 & 136 \\
\hline
\end{tabular}

Table 7: Estimated mean time (days) and standard deviation (SD) for total release of B[a]A, Chry, B[a]P and B[ghi]Per (sum of the four PAHs) from rubber crumb samples The triple horizontal line divides new crumb (samples 1-5) from crumb sampled from sporting installations (samples 6-9).

a lifetime using for each pollutant the inhalation pathway toxicological parameters that are Reference Dose $\left(\mathrm{R}_{\mathrm{f}} \mathrm{D}\right)$ for $\mathrm{HQ}$ calculation $(\mathrm{HQ}=$ $\mathrm{ADD} / \mathrm{R}_{\mathrm{f}} \mathrm{D}$ ) and Slope Factor (SF) for ECR calculation (ECR = LADD $\times$ SF) $($ Table $8 \mathrm{~A}-\mathrm{B})$. The values of these parameters are included in the ISS/ISPESL 2009 database [35] (Table 8A-B). HQs for all PAHs are summed to provide an overall Hazard Index (HI). When $\mathrm{HI} \leq 1$ there are no concern for potential adverse systemic health effects in the exposed individuals. Summing the individual ECR for all PAHs, it provides the Cumulative Excess Cancer Risk ( $\mathrm{EECR})$, that is acceptable if $<10^{-6}[36]$. In the different rubber granulates samples was found a HI range that varies between a minimum of $8.94 \times 10^{-7}$ in sample 4 and a maximum of $1.16 \times 10^{-6}$ in sample 1 (Table $8 \mathrm{~A}$ ). The $\Sigma$ ECR range goes from a minimum of $4.91 \times 10^{-9}$ for sample 6 to a maximum of $1.10 \times 10^{-8}$ for sample 1 again (Table $8 \mathrm{~B}$ ). All values were considered as acceptable. Menichini et al. [37] found an excess lifetime cancer risk of $1 \times 10^{-6}$ for an athlete with an intense 30-years activity; then despite the different parameters considered for the athlete in this study, the results are very similar.

In reality, when the ambient temperature is $25^{\circ} \mathrm{C}$ and direct sunlight exposure is present on field, rubber granulates reach a mean temperature of $60^{\circ} \mathrm{C}$, where a chronic release of PAHs occur, as seen in section 3.3. According to the high evaporation which occurs in this condition and knowing that these fields are used anyway with such temperatures, despite it should be decreased by watering, we calculate an estimate of risk for outdoor fields at $60^{\circ} \mathrm{C}$. Applying again the precautionary principle estimating the maximum risk, we consider only the central area of the field of size $18 \times 32 \mathrm{~m}\left(576 \mathrm{~m}^{2}\right)$, from now indicated as Interested Area (IA) (Figure 3), where the exchange of air at $2 \mathrm{~m}$ is irrelevant because it comes from surrounding perimeter and then it has the same toxicological characteristics. The air temperature at $2 \mathrm{~m}$ above the field is considered to have the same temperature as the granulates, according to the principle of the vertical temperature gradient. First, we calculated the quantity of crumb in a soccer field, averaging the specific weights $(\gamma)$, which were similar, of the various samples analyzed (mean $0.518 \mathrm{~g} / \mathrm{mL}$ ). Considering IA paved with synthetic turf $3 \mathrm{~cm}$ thick, the quantity of crumb of specific weight 0.518 $\mathrm{g} / \mathrm{mL}$ is $8951 \mathrm{~kg}$. To estimate risk to human health from exposure to PAHs, we expressed the toxicity of the various PAHs with respect to $\mathrm{B}[\mathrm{a}] \mathrm{P}$, in other words as Benzo(a)Pyrene Equivalent $\left(\mathrm{BaP}_{\mathrm{eq}}\right)$. We calculated the Toxic Equivalent Quantity (TEQ) by multiplying the individual PAH levels in evaporates by their Toxic Equivalency Factor 


\begin{tabular}{|c|c|c|c|c|c|c|c|c|c|c|}
\hline \multirow{2}{*}{ A } & \multirow{2}{*}{ RfD } & Sample 1 & Sample 2 & Sample 3 & Sample 4 & Sample 5 & Sample 6 & Sample 7 & Sample 8 & Sample 9 \\
\hline & & HQ & HQ & HQ & HQ & HQ & HQ & HQ & HQ & HQ \\
\hline Pyr & $3.00 \times 10^{-02}$ & $5.73 \times 10^{-07}$ & $6.80 \times 10^{-07}$ & $4.02 \times 10^{-07}$ & $6.04 \times 10^{-07}$ & $3.84 \times 10^{-07}$ & $1.66 \times 10^{-07}$ & $2.17 \times 10^{-07}$ & $1.93 \times 10^{-07}$ & $1.04 \times 10^{-06}$ \\
\hline$B(a) A$ & $2.85 \times 10^{-01}$ & $1.24 \times 10^{-08}$ & $1.71 \times 10^{-08}$ & $9.81 \times 10^{-10}$ & $4.68 \times 10^{-09}$ & $2.84 \times 10^{-09}$ & $1.23 \times 10^{-09}$ & $4.40 \times 10^{-10}$ & $5.72 \times 10^{-11}$ & $4.14 \times 10^{-09}$ \\
\hline Chry & $3.00 \times 10^{-02}$ & $2.90 \times 10^{-07}$ & $3.46 \times 10^{-07}$ & $9.32 \times 10^{-08}$ & $1.41 \times 10^{-07}$ & $7.07 \times 10^{-08}$ & $2.46 \times 10^{-08}$ & $9.30 \times 10^{-08}$ & $6.28 \times 10^{-08}$ & $9.26 \times 10^{-08}$ \\
\hline$B[b] F$ & $2.85 \times 10^{-01}$ & $1.18 \times 10^{-07}$ & $1.67 \times 10^{-07}$ & $1.22 \times 10^{-08}$ & $4.86 \times 10^{-08}$ & $1.66 \times 10^{-08}$ & $2.02 \times 10^{-08}$ & $1.33 \times 10^{-08}$ & $1.53 \times 10^{-08}$ & $1.08 \times 10^{-07}$ \\
\hline$B(k) F$ & $2.85 \times 10^{-02}$ & $7.22 \times 10^{-08}$ & $1.28 \times 10^{-07}$ & $7.26 \times 10^{-09}$ & $5.37 \times 10^{-08}$ & $3.75 \times 10^{-08}$ & $1.35 \times 10^{-08}$ & $2.38 \times 10^{-08}$ & $6.50 \times 10^{-08}$ & $3.84 \times 10^{-07}$ \\
\hline$B(a) P$ & $3.14 \times 10^{+00}$ & $2.48 \times 10^{-10}$ & $4.49 \times 10^{-10}$ & $1.16 \times 10^{-10}$ & $2.22 \times 10^{-10}$ & $1.60 \times 10^{-10}$ & $2.56 \times 10^{-10}$ & $5.83 \times 10^{-11}$ & $5.00 \times 10^{-11}$ & $6.40 \times 10^{-10}$ \\
\hline B(ghi)Per & $3.00 \times 10^{-02}$ & $9.12 \times 10^{-08}$ & $4.54 \times 10^{-08}$ & $4.00 \times 10^{-08}$ & $4.23 \times 10^{-08}$ & $5.91 \times 10^{-08}$ & $5.49 \times 10^{-08}$ & $2.42 \times 10^{-08}$ & $3.48 \times 10^{-08}$ & $4.80 \times 10^{-08}$ \\
\hline HI & & $1.16 \times 10^{-06}$ & $1.38 \times 10^{-06}$ & $5.56 \times 10^{-07}$ & $8.94 \times 10^{-07}$ & $5.71 \times 10^{-07}$ & $2.81 \times 10^{-07}$ & $3.71 \times 10^{-07}$ & $3.71 \times 10^{-07}$ & $1.68 \times 10^{-06}$ \\
\hline \multirow{2}{*}{ B } & \multirow{2}{*}{ SF } & Sample 1 & Sample 2 & Sample 3 & Sample 4 & Sample 5 & Sample 6 & Sample 7 & Sample 8 & Sample 9 \\
\hline & & ECR & ECR & ECR & ECR & ECR & ECR & ECR & ECR & ECR \\
\hline$B(a) A$ & $6.00 \times 10^{-01}$ & $6.06 \times 10^{-10}$ & $8.38 \times 10^{-10}$ & $4.79 \times 10^{-11}$ & $2.29 \times 10^{-10}$ & $1.39 \times 10^{-10}$ & $6.00 \times 10^{-11}$ & $2.15 \times 10^{-11}$ & $2.80 \times 10^{-12}$ & $2.02 \times 10^{-10}$ \\
\hline Chry & $6.10 \times 10^{-03}$ & $1.53 \times 10^{-11}$ & $1.81 \times 10^{-11}$ & $4.87 \times 10^{-12}$ & $7.38 \times 10^{-12}$ & $3.70 \times 10^{-12}$ & $1.29 \times 10^{-12}$ & $4.86 \times 10^{-12}$ & $3.29 \times 10^{-12}$ & $4.84 \times 10^{-12}$ \\
\hline$B[b] F$ & $6.00 \times 10^{-01}$ & $5.77 \times 10^{-09}$ & $8.16 \times 10^{-09}$ & $5.97 \times 10^{-10}$ & $2.37 \times 10^{-09}$ & $8.12 \times 10^{-10}$ & $9.87 \times 10^{-10}$ & $6.48 \times 10^{-10}$ & $7.48 \times 10^{-10}$ & $5.29 \times 10^{-09}$ \\
\hline$B(k) F$ & $3.10 \times 10^{-02}$ & $1.82 \times 10^{-11}$ & $3.23 \times 10^{-11}$ & $1.83 \times 10^{-12}$ & $1.36 \times 10^{-11}$ & $9.48 \times 10^{-12}$ & $3.40 \times 10^{-12}$ & $6.02 \times 10^{-12}$ & $1.64 \times 10^{-11}$ & $9.71 \times 10^{-11}$ \\
\hline$B(a) P$ & $7.32 \times 10^{+00}$ & $1.62 \times 10^{-09}$ & $2.94 \times 10^{-09}$ & $7.59 \times 10^{-10}$ & $1.46 \times 10^{-09}$ & $1.05 \times 10^{-09}$ & $1.68 \times 10^{-09}$ & $3.82 \times 10^{-10}$ & $3.28 \times 10^{-10}$ & $4.20 \times 10^{-09}$ \\
\hline$D(a h) A$ & $7.30 \times 10^{+00}$ & $2.93 \times 10^{-09}$ & $2.29 \times 10^{-09}$ & $1.22 \times 10^{-09}$ & $4.60 \times 10^{-10}$ & $2.70 \times 10^{-09}$ & $2.18 \times 10^{-09}$ & $6.90 \times 10^{-10}$ & $8.52 \times 10^{-10}$ & $3.62 \times 10^{-09}$ \\
\hline$\sum$ ECR & & $1.10 \times 10^{-08}$ & $1.43 \times 10^{-08}$ & $2.63 \times 10^{-09}$ & $4.54 \times 10^{-09}$ & $4.71 \times 10^{-09}$ & $4.91 \times 10^{-09}$ & $1.75 \times 10^{-09}$ & $1.95 \times 10^{-09}$ & $1.34 \times 10^{-08}$ \\
\hline
\end{tabular}

Table 8. Hazard Quotient (HQ) and Excess Cancer Risk (ECR) values calculated using the Reference Dose $(R D)$ for $H Q$ calculation $(H Q=A D D / R D)(T a b l e ~ 8 A)$ and Slope Factor (SF) for ECR calculation (ECR = LADD x SF) (Table 8B). The values of the RD and SF are included in the ISS/ISPESL 2009 database (ISS/ISPESL, 2009). HQs for all PAHs are summed to provide an overall Hazard Index $(\mathrm{HI})$. When $\mathrm{HI} \leq 1$ there are no concern for potential adverse systemic health effects in the exposed individuals. Summing the individual ECR for all PAHs, it provides the Cumulative Excess Cancer Risk ( $\sum$ ECR), that is acceptable if $<10^{-6}$ (USEPA, 2009) [39].

\begin{tabular}{|c|c|c|c|c|c|c|c|c|c|}
\hline & Sample 1 & Sample 2 & Sample 3 & Sample 4 & Sample 5 & Sample 6 & Sample 7 & Sample 8 & Sample 9 \\
\hline TEQ (ng/g) & 0.59 & 0.19 & 0.15 & 0.14 & 0.25 & 0.30 & 0.32 & 0.24 & 0.98 \\
\hline
\end{tabular}

Table 9. Toxicity Equivalent (TEQ) in benzo(a)pyrene equivalents $\left(\mathrm{BaP}_{\text {eq }}\right)$ in evaporate of crumb samples.

(TEF). This data was only calculated for PAHs that showed limited variability in the three replicates of evaporates, as mentioned above. Thus, the TEQ is based on Chry $(\mathrm{TEF}=0.01), \mathrm{B}[\mathrm{a}] \mathrm{A}(\mathrm{TEF}=0.1), \mathrm{B}[\mathrm{a}] \mathrm{P}$ $(\mathrm{TEF}=1)$ and $\mathrm{B}$ [ghi]Per $(\mathrm{TEF}=0.01)$ [38-40] making it underestimated, as many other compounds with known TEF were found in the evaporates. The TEQ for each sample (Table 9) was calculated using the following formula:

TEQ $(n g / g)=\mathrm{B}[\mathrm{a}] \mathrm{A} \times 0.10+$ Chry $\times 0.01+\mathrm{B}[\mathrm{a}] \mathrm{P} \times 1.00+\mathrm{B}[$ ghi $]$ Per $\times 0.01$

IA use $8951 \mathrm{~kg}$ of rubber crumb and we estimated the TEQ in $\mu \mathrm{g}$ referred to the crumb evaporates of the different fields at an average air temperature of $25^{\circ} \mathrm{C}$ (Table 10A). Estimating evaporation up to a height of $2 \mathrm{~m}$, we have a volume of $1152 \mathrm{~m}^{3}\left(576 \mathrm{~m}^{2} \times 2 \mathrm{~m}\right)$. Table 10B shows the results in $\mu \mathrm{g} / \mathrm{m}^{3}$ obtained dividing the TEQ of evaporates of the rubber crumb samples $(\mu \mathrm{g})$ by the estimated volume of air $\left(\mathrm{m}^{3}\right)$ above the field. Knowing that an athlete inhalation rate is around $3.6 \mathrm{~m}^{3}$ per hour [41], the TEQ inspired by him in a standard two-hour workout was calculated on the basis of that assumption. In $2 \mathrm{~h}$ of training, the daily intake of $\mathrm{BaP}$ of an athlete is showed in Table 10C. If a player trains for $2 \mathrm{~h}$ a day, three times a week, five times for professionals, plus the match, his estimated intake of PAHs as TEQ ranged from $31.2 \mu \mathrm{g} /$ week (sample 4) to $219.2 \mu \mathrm{g} /$ week (sample 9), for an average weekly exposure of $8 \mathrm{~h}$ (Table 10D). Dividing this by 7 days we obtain $4.46-$ $31.3 \mu \mathrm{g} /$ day of $\mathrm{BaP}_{\text {eq }}$ inhaled as daily mean dose, not considering other $\mathrm{PAH}$ inputs for the athletes (Table 10E). For a $70 \mathrm{~kg}$ athlete, we obtain an intake of $0.06-0.45 \mu \mathrm{g} / \mathrm{kg}$ bw of $\mathrm{BaP}_{\text {eq }}$ per day (Table 10F). Since the release of PAHs is continuous and constant throughout the life of the field (Table 6), a chronic exposure of 0.06 to $0.44 \mu \mathrm{g} / \mathrm{kg}$ bw per day $\mathrm{BaP}$ for a $70 \mathrm{~kg}$ athlete should not be underestimated. In fact recent studies have shown that $0.57-5.00 \mathrm{ng} / \mathrm{kg}$ bw per day is a virtually safe dose of $\mathrm{B}[\mathrm{a}] \mathrm{P}$ in food, which implies a risk of $1 \times 10^{-6}$ (one person in a million will develop cancer after chronic exposure). Considering that, generally, carcinogenic PAHs are about 10 -fold higher than the $\mathrm{B}[\mathrm{a}]$ $\mathrm{P}$ alone, the carcinogenicity increases and a virtually safe dose of $\mathrm{B}[\mathrm{a}]$ $\mathrm{P}$, as an indicator of carcinogenic PAHs in food, would be in the range $0.06-0.50 \mathrm{ng} / \mathrm{kg}$ bw per day [42], theoretically 1000 times lower than the range of 0.06 to $0.45 \mu \mathrm{g} / \mathrm{kg}$ bw per day found in this study.

\section{Conclusions}

Rubber crumb derived from recycled tyres, like the tyres themselves, should be considered non-hazardous special waste. The literature and the present study show that crumb contains PAHs and heavy metals. Fine dust may become airborne and leachate may filter into the soil. The magnitude of human exposure depends on chemicals of concern concentration in field, exposure parameters describing human physiology (e.g. dermal contact, body weight) and population-specific parameters describing exposure behaviour (exposure frequency, duration). Randomly ingested crumb may release these compounds in the digestive tract. Most of all, evaporation at high temperatures may expose users of sports grounds, who are often children between 5 and 13 years of age, in a very sensitive phase of growth, to many of these toxic compounds.

The results of the present study demonstrate that PAHs are continuously released from rubber crumb through evaporation. Athletes frequenting grounds with synthetic turf are therefore exposed to chronic toxicity from PAHs. The main conclusion we can draw from this preliminary study, which will be validated by further field and laboratory research, is that although synthetic turf offers various advantages over natural grass, the quantity of toxic substances it releases when heated does not make it safe for public health. When we extrapolated the data obtained in laboratory, the toxicity equivalent (TEQ) of the different compounds evaporating from the crumb was far from negligible and would contribute substantially to an athlete's total daily PAH intake. In fact, all rubber crumb samples of this study exceeded the Dlgs. 152/2006 [8] for B[b]F, B[ghi]Per and Zn, but all 
Citation: Marsili L, Coppola D, Bianchi N, Maltese S, Bianchi M (2015) Release of Polycyclic Aromatic Hydrocarbons and Heavy Metals from Rubber Crumb in Synthetic Turf Fields: Preliminary Hazard Assessment for Athletes. J Environ Anal Toxicol 5: 265. doi: 10.4172/2161-0525.1000265

Page 8 of 9

\begin{tabular}{|c|c|c|c|c|c|c|c|c|c|}
\hline & Sample 1 & Sample 2 & Sample 3 & Sample 4 & Sample 5 & Sample 6 & Sample 7 & Sample 8 & Sample 9 \\
\hline A) TEQ $(\mu \mathrm{g})$ & 5281 & 1701 & 1343 & 1253 & 2238 & 2685 & 2864 & 2148 & 8772 \\
\hline B) TEQ $\left(\mu \mathrm{g} / \mathrm{m}^{3}\right)$ & 4.584 & 1.477 & 1.166 & 1.088 & 1.943 & 2.331 & 2.486 & 1.865 & 7.615 \\
\hline $\begin{array}{l}\text { C) TEQ }(\mu \mathrm{g}) \text { in } 2 \mathrm{~h} \text { of } \\
\text { activity }\end{array}$ & 33.00 & 10.60 & 8.40 & 7.80 & 14.00 & 16.80 & 17.90 & 13.40 & 54.80 \\
\hline $\begin{array}{l}\text { D) TEQ }(\mu \mathrm{g}) \text { one week (8 } \\
\text { h) of activity }\end{array}$ & 132.00 & 42.40 & 33.60 & 31.20 & 56.00 & 67.20 & 71.60 & 53.60 & 219.80 \\
\hline E) TEQ $(\mu g)$ a day & 18.86 & 6.06 & 4.80 & 4.46 & 8.00 & 9.60 & 10.23 & 7.66 & 31.30 \\
\hline $\begin{array}{l}\text { F) TEQ ( } \mu \mathrm{g} / \mathrm{kg} \text { bw per day) } \\
\text { for a } 70 \mathrm{~kg} \text { athlete }\end{array}$ & 0.27 & 0.09 & 0.07 & 0.06 & 0.11 & 0.14 & 0.15 & 0.11 & 0.45 \\
\hline
\end{tabular}

Table 10. Toxicity Equivalent (TEQ) in benzo(a)pyrene equivalents $\left(B a P_{\text {eq }}\right.$ in $\left.\mu \mathrm{g}\right)$ : $\left.A\right)$ theoretically released by rubber crumb in the Interested $A$ rea $(\mathrm{I} A)$; $\left.B\right)$ per $\mathrm{m}^{3}$ of air over IA; C) inhaled by an athlete in $2 \mathrm{~h}$ of activity; D) inhaled by an athlete in an average weekly exposure (8h) of activity; E) inhaled by an athlete as daily mean dose and F) a daily intake for a $70 \mathrm{~kg}$ athlete.

PAHs, except Chry, were over the threshold in almost one synthetic field. It must be underlined that this preliminary hazard assessment overestimates the PAH contribution of the field because the input from the wide variety of anthropogenic and crustal sources were not considered and then, this theoretical approach must be considered as an extreme worst case screening.

\section{Acknowledgments}

We thank Prof. Eros Bacci for expert guidance in support of this research.

\section{References}

1. Kolitzus HJ (2007) Artificial turf surfaces for soccer. What owners of soccer pitches should know about artificial turf. IST Switzerland, United States Sports Surfacing Laboratory USSL $1-29$.

2. Claudio L (2008) Synthetic turf: health debate takes root. Environ Health Perspect 116: A116-122.

3. Verschoor AJ (2007) Leaching of zinc from rubber infill on artificial turf (footbal pitches). National Institute for Public Health and the Environment, The Netherlands. RIVM Report 601774001. 1-55

4. Beausoleil M, Price K, Muller C (2008) Chemicals in outdoor artificial turf: a health risk for users. BISE 19:1-11.

5. van Rooij JG, Jongeneelen FJ (2010) Hydroxypyrene in urine of football players after playing on artificial sports field with tire crumb infill. Int Arch Occup Environ Health 83: 105-110.

6. Ministerial Circular (2005) Ministero dell'Ambiente e della Tutela del Territorio Indicazioni relative ai materiali riciclati e beni e manufatti ottenuti con materiale riciclato, proveniente da articoli in gomma, ai sensi del decreto ministeriale 8 maggio 2003, n. 203. Italian Official Journal 173

7. DIN 18035-7 (2002) Sports grounds part 7; synthetic turf areas. Determination of environmental compatibility. Deutsches Institut für Normung eV, Berlin Germany.

8. Dlgs (2006) $152 / 2006$ of $3 / 04 / 2006$. Rules in environmental field. Italian Official Journal 88

9. LND (2013) I campi di calcio in erba artificiale - Regolamento per la realizzazione di un campo da calcio in erba artificiale di ultima generazione. Rome Italy $1-45$

10. Swedish Chemicals Inspectorate. Synthetic turf from a chemical perspective a status report. Sweden: Sundbyberg 2006.

11. Gomes J, Mota H, Bordado J, Cadete M, Sarmento G, et al. (2010) Toxicological assessment of coated versus uncoated rubber granulates obtained from used tires for use in sport facilities. J Air Waste Manag Assoc 60: 741-746.

12. CDC (2008) Potential exposure to lead in artificial turf: public health issues actions, and recommendations.

13. Bocca B, Forte G, Petrucci F, Costantini S, Izzo P (2009) Metals contained and leached from rubber granulates used in synthetic turf areas. Sci Total Environ 407: 2183-2190.

14. Cheng H, Hu Y, Reinhard M (2014) Environmental and health impacts of artificial turf: a review. Environ Sci Technol 48: 2114-2129.

15. Li X, Berger W, Musante C, Mattina MI (2010) Characterization of substances released from crumb rubber material used on artificial turf fields. Chemosphere
80: $279-285$

16. Birkholz DA, Belton KL, Guidotti TL (2003) Toxicological evaluation for the hazard assessment of tire crumb for use in public playgrounds. J Air Waste Manag Assoc 53: 903-907.

17. Ginsberg G, Toal B, Simcox N, Bracker A, Golembiewski B, et al. (2011) Human health risk assessment of synthetic turf fields based upon investigation of five fields in Connecticut. J Toxicol Environ Health A 74:1150-1174.

18. Ginsberg G, Toal B, Kurland T (2011) Benzothiazole toxicity assessment in support of synthetic turf field human health risk assessment. J Toxicol Environ Health A 74: 1175-1183.

19. Simcox N, Bracker A, Ginsberg G, Toal B, Golembiewski B, et al. (2011) Synthetic turf field investigation in Connecticut. J Toxicol Environ Health $A$ $74: 1133-1149$

20. European Community (2005) Directive 2005/69/EC of the European Parliament and of the Council. Amending for the 27th time Council Directive 76/769/EEC on the approximation of the laws, regulations and administrative provisions of the Member States relating to restrictions on the marketing and use of certain dangerous substances and preparations (polycyclic aromatic hydrocarbons in extender oils and tyres). Official Journal of the European Union L323.

21. Griest WH, Caton JE (1983) Extraction of polycyclic aromatic hydrocarbons for quantitative analysis. Handbook of Polycyclic Aromatic Hydrocarbons. (Ed) Biørseth A 95-148.

22. Holoubek I, Paasivirta J, Maatela P, Lahtipera M, Holoubkova I, et al. (1990) Comparison of extraction methods for polycyclic aromatic hydrocarbons determination in sediments. Toxicol Environ Chem 25:137-154

23. Marsili L, Fossi MC, Casini S, Savelli C, Jimenez B, et al. (1997) Fingerprin of polycyclic aromatic hydrocarbons in two populations of southern sea lions (Otaria flavescens). Chemosphere 34: 759-770.

24. Berardi S, Bemporad E, Gherardi M, Mariani M (2010) Intrusione di vapori da suolo contaminato: un approccio alternativo per la valutazione del rischio. Ambiente e sicurezza 2:71.

25. Boekhold AE (2008) Ecological risk assessment in legislation on contaminated soil in The Netherlands. Sci Total Environ 406: 518-522.

26. Zhang JJ, Han IK, Zhang L, Crain W (2008) Hazardous chemicals in synthetic turf materials and their bioaccessibility in digestive fluids. J Expo Sci Environ Epidemiol 18: 600-607.

27. DEC (2006) 6 NYCRR part 375 - Environmental Remediation Program.

28. USEPA (1984) Health effects assessment for polycyclic aromatic hydrocarbons (PAH). Cincinnati, OH: U.S. Environmental Protection Agency, Office of Health and Environmental Assessment, Environmental Criteria and Assessment Office. First Draft. ECAO-CIN-H013.

29. IARC Working Group on the Evaluation of Carcinogenic Risks to Humans (2010) Some non-heterocyclic polycyclic aromatic hydrocarbons and some related exposures. IARC Monogr Eval Carcinog Risks Hum 92: 1-853.

30. IPCS (1998) Environmental Health Criteria 202: selected non-heterocyclic polycyclic aromatic hydrocarbons. International Programme on Chemical Safety, World Health Organization, Geneva, Switzerland.

31. NRCC (1983) Polycyclic aromatic hydrocarbons in the aquatic environment formation, sources, fate and effects on aquatic biota. NRCC Report. 18981: 1- 209

32. NTP (2005) Report on Carcinogens. (11 $1^{\text {th }}$ edtn) Research Triangle Park NC: U.S. Department of Health and Human Services, Public Health Service, 
Citation: Marsili L, Coppola D, Bianchi N, Maltese S, Bianchi M (2015) Release of Polycyclic Aromatic Hydrocarbons and Heavy Metals from Rubber Crumb in Synthetic Turf Fields: Preliminary Hazard Assessment for Athletes. J Environ Anal Toxicol 5: 265. doi: 10.4172/2161-0525.1000265

Page 9 of 9

National Toxicology Program.

33. European Community (2006) Regulation (EC) No 1881/2006. Setting maximum levels for certain contaminants in foodstuffs. Official Journal of the European Union L364.

34. APAT - Italian Environmental Protection Agency and Technical Services (2008) Criteri metodologici per l'applicazione dell'analisi assoluta di rischio ai siti contaminati. 1-156.

35. ISS/ISPESL (2009) ISPRA/ISPESL database "Chemical/physical and toxicological properties of pollutants".

36. USEPA (2009) Risk assessment guidance for superfund volume I human health evaluation manual.

37. Menichini E, Abate V, Attias L, De Luca S, di Domenico A, et al. (2011) Artificialturf playing fields: Contents of metals, PAHs, PCBs, PCDDs and PCDFs inhalation exposure to PAHs and related preliminary risk assessment. Sci Tota
Environ 409: 4950-4957.

38. Nisbet IC, LaGoy PK (1992) Toxic equivalency factors (TEFs) for polycyclic aromatic hydrocarbons (PAHs). Regul Toxicol Pharmacol 16: 290-300.

39. USEPA (1993) Provisional guidance for quantitative risk assessment of Polycyclic Aromatic Hydrocarbons, US Environmental Protection Agency, Research Triangle Park, NC, EPA-600/R-93/089.

40. Larsen JC, Larsen PB (1998) Chemical carcinogens, in: Hester, R.E., Harrison, R.M. (Eds.), Air pollution and health. Royal Society of Chemistry, Cambridge, UK 33-56.

41. USEPA (1997) Exposure factors handbook. National Center for Environmental Assessment. Office of Research and Development 1216.

42. Kulhnek A, Trapp S, Sismilich M, Jank J, Zimovi M (2005) Crop-specific human exposure assessment for polycyclic aromatic hydrocarbons in Czech soils. Sc Total Environ 339: 71-80. 